DOI: $10.17805 / z p u .2016 .3 .18$

\title{
Организационная культура российской гуманитарной научной организации (на примере Института психологии РАН)*
}

\author{
A. E. ВОРОБЬЕВА \\ (ИНСТИТУТ ПСИХОЛОГИИ РОССИЙСКОЙ АКАДЕМИИ НАУК)
}

В статье представлено исследование организационной культуры научной организации как части национальной научно-исследовательской культуры. Особую актуальность она приобретает в ситуации современного реформирования российской науки. Организационная культура понимается как характеристика организации, в которой особую роль играют ценности. Отмечается специфика организационной культуры в связи с отраслью деятельности организации. Ценности конкретной научной организации определяются не только ценностями мировой науки, но и ценностями национальной культуры. Для функционирования научных организаций в советский период было характерно следующее: результат деятельности трудно применим на практике, высокая субъективность оценки квалификационных работ, свободный режим труда, недостаточность материального оснащения. На современном этапе отмечаются следующие проблемы в российской науке: низкие зарплата и социально-экономический статус, старение кадров, двойная занятость и др.

Представлены результаты исследования, выполненного автором в 2015 г. на четырех фокус-группах, состоящих из 20 сотрудников разных лабораторий Института психологии РАН. В качестве теоретического основания исследования выбрана целостная концепция, относящаяся к школе моделирования, - концепция организационной культуры Э. Х. Шейна. На ее основе был составлен план группового интервью. Контент-анализ позволил выявить ценности и базовые представления организационной культуры института во мнениях сотрудников. Наиболее значимыми ценностями для

* Работа выполнена при поддержке РГНФ (проект «Культура российского научного общества: интеграция индивидуального и организационного уровней», грант № 13-06-00688а).

The article was prepared with financial support from the Russian Foundation for the Humanities, Grant No. 13-06-00688a "Culture of the Russian scientific community: the integration of individual and organizational levels". 
ученых оказались свобода и сохранение традиций, а наиболее значимыми базовыми представлениями - свобода и научная школа.

Установлено, что в целом в организационной культуре современной российской гуманитарной научной организации во многом сохраняются элементы, унаследованные ею от советской гуманитарной научной организации.

Ключевые слова: Институт психологии РАН; организационная культура; базовые представления; гуманитарная научная организация; научная культура; ценности науки

\section{BВЕАЕНИЕ}

$\mathrm{H}^{\mathrm{s}}$ ынешний период экономического развития называют экономикой знаний (Аллахвердян, 2014), поэтому изучение социальных институтов, порождающих новое знание, является важной задачей. Отмечается, что в настоящее время российская наука утратила социально значимые функции (Семенов, 2008), она не получает четкого социального заказа от власти, а власть не получает от нее конкретных предложений (Юревич, Цапенко, 2010). В условиях реорганизации российской науки, осуществляемой преимущественно на основе зарубежных моделей, важной задачей является привлечение внимания к вопросам национальной специфики научной деятельности в России. Хотя существующая литература (Иванова, 2001; Аежина, 2006, 2008; Аежина, Грэхем, 2009) позволяет составить системное описание структуры институтов российской науки, она не дает представления о факторе организационной культуры.

Аанная работа является частью исследовательского проекта «Культура российского научного сообщества: интеграция индивидуального и организационного уровней» (2013-2015), цель которого состоит в том, чтобы дать развернутую системную характеристику российской научно-исследовательской культуры: ее идейной составляющей, институциональной структуры, ценностных ориентаций российских ученых. Анализ организационной культуры российской гуманитарной научной организации на примере Института психологии РАН является задачей нашего исследования.

\section{ТЕОРЕТИЧЕСКИЕ ОСНОВАНИЯ ИССАЕАОВАНИЯ}

Первые работы, в которых рассматривалась организационная культура производственного предприятия, появились в начале 50-х годов XX в. (Jaques, 1951; Whyte, 1956), однако наиболее активные исследования начались лишь в 1980-е годы (Ouchi, 1981; Deal, Kennedy, 1982; Peters, Waterman, 1982).

Организационная культура понимается разными авторами либо как то, чем организация обладает, либо как то, чем она является (Иипатов, 1997). В нашей работе мы будем придерживаться первого понимания организационной культуры и рассматривать ее как совокупность принятых форм поведения, ритуалов и мифов, которые соответствуют разделяемым сотрудниками ценностям (Michon, Stern, 1985). Анализ различных трактовок организационной культуры, выполненный О. Г. Тихомировой, показал, что ценности признаются центральной составляющей большинства из них (Тихомирова, 2008).

Выделяют три основных теоретических подхода к изучению организационной культуры: 1) символический (символы используются для уменьшения неопределенности); 2) когнитивный (участники вовлечены в непрерывный процесс порождения смысла существования); 3) целостный (совокупность объективных свойств 
и психологической среды) (Mohan, 1993). Существует и иное деление направлений изучения организационной культуры: 1) поведенческая школа (закономерности создания норм); 2) школа эффективности (роль культуры в әффективности деятельности); 3) школа моделирования (типологии, модели, методы оценки) (Тихомирова, 2008).

С. А. Аипатов отмечает, что подход к пониманию организационной культуры, предложенный Э. Х. Шейном (Шейн, 2002), является наиболее популярным (Аипатов, 1997). Аанный подход является целостным и относится к школе моделирования. Структура организационной культуры рассматривается в виде пирамиды, в основании которой лежат базовые представления (парадигма, философия и идеология организации, корпоративная религия), на них базируются провозглашаемые ценности, верхний слой - артефакты (внешние проявления жизни организации: внешний вид сотрудников, их речь, организация рабочего пространства, корпоративная символика, традиционные мероприятия и т. п.) (Шейн, 2002). Аанный подход был выбран нами в качестве теоретического основания исследования.

Анализ организационной культуры может осуществляться либо в идеографическом, либо в формализованном подходе. Как предлагает Э. Х. Шейн, при анализе организационной культуры следует проводить фокус-группы с рядовыми сотрудниками (Шейн, 2002).

Организации, относящиеся к разным сферам деятельности, будут обладать очевидно различными культурами. О. Г. Тихомирова приводит сравнительные данные относительно специфики организационной культуры для промышленных, топливно-энергетических, финансовых, консалтинговых, торговых, строительных, транспортных, коммуникационных, развлекательных, государственных компаний, образовательные и научные учреждения в этом перечне не упоминаются (Тихомирова, 2008). Начиная с 1980-х годов наблюдается больше число работ по проблемам научных коллективов, в которых рассматриваются факторы эффективности научного труда, проблема мотивации, управления научными организациями, межличностных отношений в научных коллективах, адаптации молодых специалистов и др. (Белкин и др., 1987; Аук, 1982; Проблема эффективности ... , 1984), однако работ, напрямую посвященных проблеме организационной культуры научного учреждения, нами обнаружено не было.

Характеризуя субкультуры различных подразделений, О. Г. Тихомирова отмечает, что сотрудники отдела, занятого разработками новых технологий, часто имеют научную степень и занимаются творческим трудом, они в большой мере ориентированы на служение науке и в малой на взаимодействие со внешней средой (Тихомирова, 2008: 85). Отмеченная особенность, с нашей точки зрения, может быть отнесена к специфике не только конструкторских отделов, но и научных учреждений в целом. В социально-психологических исследованиях отечественной науки, активно развивавшихся с 1970-х годов, отмечены следующие особенности функционирования научных коллективов: недостаточный учет организационноуправленческих навыков научных работников при назначении их на должность руководителя научного подразделения, сложность адаптации молодого ученого в коллективе по причине оторванности системы подготовки научных кадров от научных школ, сложившейся еще во второй половине XIX в., идеализированные 
представления о научной деятельности у молодых специалистов, их неготовность к рутинной работе, затянутость периода адаптации молодого специалиста (до пяти-семи лет при том, что после четырех лет работы у «неофита» должно наступать завершение самоопределения, сосредоточение на основной тематике, наступление периода продуктивной работы), сокращающего таким образом период активной деятельности ученого (наиболее благоприятным для начала самостоятельной деятельности в науке назван возраст 25-30 лет в связи с тем, что способность воспринимать новые идеи после 30 лет начинает уменьшаться, а умение использовать информацию начинает возрастать) (Белкин и др., 1987: 124, 133). Советский гуманитарный научно-исследовательский институт традиционно обладал специфическим режимом и условиями труда сотрудников: два присутственных и три библиотечных дня, одно рабочее место на несколько сотрудников, постоянные чаепития на рабочих местах. Еще одной характерной особенностью была атмосфера интеллектуализма, проявлявшаяся в культе красоты мысли, которая была важнее практической применимости (Юревич, 2015).

Организационная культура представляет собой часть культуры нации, региона, государства, общества и во многом ими определяется (влияние этого фактора на организационную культуру является более сильным, чем влияние создателя организации, квалификации ее сотрудников и т. А.) (Тихомирова, 2008: 54). В структуре ценностей восточных культур, которые М. С. Каган считает функционирующими и в России, первостепенное значение имеют уровень в структуре власти, скромность, уважение к старшим, коллективная ответственность, авторитаризм и др., второстепенное значение имеют уважение к молодежи, образование и др., третьестепенное - деньги, активность, настойчивость, эффективность, качество и др., к несущественным относятся первенство и др. (Каган, 1997: 146-147). Эти ценности присутствуют и в организационной культуре российских учреждений.

Ценности научных сообществ конкретных стран определяются наряду с ценностями мировой науки и ценностями национальной культуры. Ценностный элемент национальной научно-исследовательской культуры способен пережить значительные социальные потрясения, примером тому служит судьба Российской академии наук в периоды 1917 г. и 1991 г. (Коннов, 2014).

На примере структуры ценностей в психологической науке попробуем соотнести ценности культуры и ценности организации, рассмотренные выше, с ценностями мировой науки и научного сообщества конкретной страны. А. В. Юревич выделяет следующие уровни ценностей в психологической науке: 1) универсальные ценности познания и базовые ценности научного сообщества (истина, объяснение, предсказание, контроль, принадлежность к научному сообществу и др.); 2) ценностные основания социогуманитарных дисциплин (социальная релевантность, политические ценности и др.); 3) специфические ценности психологии (ориентация на точные науки / самобытность, ценности исследовательской / практической психологии и др.); 4) внутренние ценности различных школ и направлений (специфичные для конкретной школы социальные и когнитивные установки); $5)$ ценности, воплощенные в изучении конкретных психологических проблем (повышение интеллекта, развитие способностей и др.); 6) личные ценности психологов (преодоление комплексов, интерпретация результатов и др.) (Юревич, 
2008: 38). В данной системе уровней ценности культуры относятся ко второму уровню, а ценности конкретной научной организации могут быть отнесены к четвертому уровню или даже выделены в самостоятельный уровень, расположенный между третьим и четвертым, если в научной организации сосуществуют разные научные школы.

Аля российской научной среды всегда было характерно острое реагирование на нужды общества, но создаваемый ею продукт не выглядел простым, понятным и доступным практике, а требовал дополнительного анализа, извлечения основных идей из громоздких, многословных трудов (Иевченко, 2006). А. С. Чернышев в своем анализе перспектив отечественной психологии отмечает принципиальное отличие психологического знания от естественно-научного, заключающееся в сложности непосредственного применения на практике и необходимости создания опосредствующих социальных структур (Чернышев и др., 2015). А. Х. Балзер характеризовал российскую социогуманитарную науку как в большой степени теоретическую, закрытую (с недоступностью результатов), менторскую (с предпочтением старых тем) (Balzer, 1989). Специфической особенностью отечественной психологической науки, отличающей ее от западной, также называется приоритет теории над экспериментом, движение научной мысли сверху вниз, «не конвейерная» организация науки, меньшая жесткость критериев оценки работ (Ушаков, Валуева, 2006). Однако А. Г. Аллахвердян отмечает, что в российских гуманитарных науках системы присуждения ученой степени носят субъективный и персонализированный характер (Аллахвердян, 2014: 150).

Обобщая вышеизложенное, можно сделать вывод, что для российских гуманитарных научных организаций традиционно характерно следующее: свободный режим труда, недостаточность материального оснащения, низкий социальноэкономический статус работника, высокий субъективизм в оценке продукта труда и затрудненность его практического применения.

Национальную специфику социогуманитарной науки кроме ценностей задают также конкретные социальные условия, в которых она существует (Юревич, Цапенко, 2010). К макросоциальным особенностям современной российской науки А. В. Юревич относит более низкую по сравнению с зарубежными коллегами зарплату ученых, а также их положение в обществе (Юревич, 2015: 124). Наука в целом развивается в условиях «экономического занавеса», сменившего идеологический, препятствующего интеграции российских ученых в мировую науку (публикациям в международных журналах препятствует также языковой фактор) (Юревич, 2008). Кроме того, отмечается разрыв науки с производством, утечка идей и технологий, сокращение общей численности ученых, их двойная занятость, старение научных кадров, расцвет паранауки, деградация профессиональной морали, институциональные конфликты в научной среде и т. А.

Мы выдвигаем следующую гипотезу нашего исследования: в организационной культуре современной российской гуманитарной научной организации сохраняются элементы, унаследованные ею от советской гуманитарной научной организации. Контргипотезой будет принципиальное отличие современной российской гуманитарной научной организации от организаций такого типа, существовавших в советский период. 


\section{ПРОГРАММА ИССАЕАОВАНИЯ И ЕГО РЕЗУАЬТАТЫ}

В структуре Института психологии РАН насчитывается 12 лабораторий: лаборатория инженерной психологии и эргономики, лаборатория психологии познавательных процессов и математической психологии, лаборатория психофизиологии им. В. Б. Швыркова, лаборатория социальной и экономической психологии, лаборатория психологии личности, лаборатория психологии развития, лаборатория психологии труда, лаборатория психологии и психофизиологии творчества, лаборатория психологии посттравматического стресса, лаборатория психологии речи и психолингвистики, лаборатория истории психологии и исторической психологии, лаборатория психологии способностей и ментальных ресурсов им. В. Н. Аружинина. Штат Института психологии насчитывает порядка 150 человек. Из них женщин $60 \%$, а мужчин $40 \%$.

В 2015 г. нами было проведено четыре фокус-группы с общей численностью участников 20 человек. Из них представителей лаборатории психологии познавательных процессов и математической психологии -1 человек, лаборатории психофизиологии им. В. Б. Швыркова -3 человека, лаборатории социальной и экономической психологии -5 человек, лаборатории психологии развития -4 человека, лаборатории психологии труда -3 человека, лаборатории психологии посттравматического стресса - 1 человек, лаборатории психологии речи и психолингвистики - 2 человека, лаборатории истории психологии и исторической психологии 1 человек. Первая фокус-группа была проведена с целью апробации и коррекции плана интервью. В ней приняли участие 5 человек (2 женщины, 3 мужчин). Во второй фокус-группе приняли участие 8 человек (2 мужчин, 6 женщин), в третьей 4 человека (2 мужчин, 2 женщин), в четвертой -3 человека (1 мужчина, 2 женщины).

Модератором объяснялись цели исследования, на листе ватмана визуализировалась в виде пирамиды структура организационной культуры по Э. Шейну, объяснялись ее компоненты. Аалее им предлагалось охарактеризовать отдельные параметры организационной культуры (наличие субкультур в организации, ощущение организации как единого целого, манера общения с начальством и коллегами, дистанция власти, формы контроля, продукты деятельности, проблемы организации, традиции, ценности, базовые представления), а модератор кратко записывал их высказывания в соответствующих частях изображения структуры организационной культуры и фиксировал на диктофон. Продолжительность фокус-группового интервью составляла 1 час.

Выбор в качестве модератора сотрудника той же организации обусловлен тем, что ему было легче замотивировать на участие и согласовать время проведения фокус-групп с коллегами, чем стороннему специалисту. Участие в исследовании носило исключительно добровольный характер.

В первой фокус-группе апробация показала, что использование видеокамеры для фиксации ответов снижает их откровенность, в связи с этим в последующих группах использовался диктофон. Также после апробации было принято решение отказаться от выбора из заданного списка организационных ценностей в пользу свободного генерирования сотрудниками перечня ценностей, присущих их организации.

Материал, полученный в фокус-группах, был подвергнут контент-анализу.

Анализ данных, полученных в фокус-группах, показал, что сотрудники видят миссию Института психологии в служении обществу, приращении знания, выпол- 
нении лидерской функции в своей отрасли знания, поддержании связей с другими научными организациями. Представления сотрудников о структуре института носят противоречивый характер: 1) это единый организм; 2) он разрозненный (по лабораториям, по группам, сформировавшимся вокруг отдельных харизматичных личностей, и по коллективным грантам); 3) разрозненность на уровне отдельных сотрудников (по поколениям), но единство на уровне заведующих лабораториями и дирекции. К числу причин разрозненности сотрудники относят разницу поколений, совместительство, менталитет, личность заведующего лабораторией, гранты. При этом отмечаются объединяющие коллектив научной организации факторы: общеинститутские научные семинары, итоговая сессия, гранты. Таким образом, гранты выполняют как разъединяющую, так и объединяющую функцию.

Респонденты отмечали, что в своих представлениях включают в структуру института даже те организации, которые формально в него не входят, но располагаются на его территории и имеют тесные связи с институтом: столовая, магазин «Психологическая книга», факультет психологии Государственного академического университета гуманитарных наук (ГАУГН), редакция «Психологического журнала», Высшая школа психологии. Кроме перечисленных организаций на территории Института психологии РАН присутствуют и другие (например, Институт практической психологии и психоанализа), но они не воспринимаются сотрудниками как его часть. Респонденты также отмечали, что включение в структуру института двух учебных заведений (факультета психологии ГАУГН и Высшей школы психологии), готовящих психологов, позволяет приобщать будущих специалистов к научной школе института, «выращивать» новые научные кадры. Сотрудники ощущают свою принадлежность к Институту психологии и к Академии наук в целом (упоминают в самопрезентации при знакомстве с кем-либо, делая акцент на том, что являются сотрудниками научно-исследовательского института - теоретиками, а не практиками). Таким образом, с одной стороны, сотрудниками подчеркивается чисто научный профиль организации, с другой - отмечается ее образовательная составляющая.

Отношения в коллективе характеризуются как хорошие рабочие отношения, отмечается естественное принятие разных методологических подходов, недостаток полемики. Руководство организации (респондентами отмечается «традиция директорства»в институте, поэтому можно говорить о характеристиках не только действующего руководителя, но и его предшественников) характеризуется как доступное, демократичное, защищающее и поддерживающее, находящееся в курсе дел всех подчиненных, представляющее институт во внешнем мире. Однако трансляция информации подчиненным носит опосредованный характер. По поводу контроля со стороны руководства были получены разные ответы: 1) отсутствие физических форм контроля, но при этом нет ощущения оторванности; 2) контроль зависит от положения конкретного сотрудника; 3) самоконтроль сотрудников.

Респондентами отмечается, что исследования, выполняемые в институте, делятся на актуальные и неактуальные. Относительно оценки результатов деятельности сотрудников института были получены следующие данные: продукт труда характеризуется как осязаемый (отображается в базе данных Российского индекса научного цитирования - РИНЦ) и неосязаемый (удовлетворение научного любопытства) одновременно, своевременность исполнения работы практически 
не оценивается и отдана на самоконтроль, подсчет показателей эффективности работы возможен только благодаря инструментам РИНЦ. Институт характеризуется как не очень материально ориентированный.

В качестве стратегии коррекции деятельности организации в период кризиса была отмечена необходимость популяризации научного знания, его «капсуляризация», как выразился один из респондентов, отмечается как проблема. На вопрос о текущем положении дел в организации сотрудниками института были даны ответы, фактически характеризующие положение дел в отрасли в целом: отмечается ситуация кризиса науки в целом, ее отрыв от практики. Причины этого видятся в различии ценностных систем академического сообщества и социума, недостаточности материальной базы для выполнения исследований на международном уровне. Также в качестве актуальных проблем были названы высокий социальный статус сотрудников при низком экономическом статусе, ощущение невостребованности обществом, изменение критериев оценки научного продукта, провоцирующее снижение его качества. Однако в целом кризис рассматривается сотрудниками как возможность для консолидации научного сообщества.

К числу наиболее заметных артефактов организационной культуры были отнесены отсутствие пропускной системы на входе, позитивная эмоциональная атмосфера, называние коллег по именам, относительно небольшой коллектив, наличие внутрилабораторных закрытых семинаров, активные научные дискуссии на защитах квалификационных работ. Сотрудники говорили о наличии историй, шуток, традиций в институте, т. е. «организационного фольклора». Больше всего было упоминаний именно о традициях, как сложившихся и поддерживаемых (всесоюзный институт, директорство), так и утраченных (профсоюзы, детские новогодние елки).

На основе полученных нами данных мы выделяем следующие ценности Института психологии РАН как организации: стабильность структуры, сохранение традиций, низкая значимость прибыли, свобода (как общая ценность), приращение знания, ответственность, открытость. Наибольшее число индикаторов (соответствующим числу ответов в данной категории) было получено по ценностям свободы (7 индикаторов) и сохранения традиций (5 индикаторов).

Также нам удалось выделить следующие базовые представления, лежащие в основе организационной культуры: поддержание научной школы, междисциплинарность, свобода научного поиска, человечность, среди которых наибольшее число индикаторов (по 4) было указано для научной школы и свободы.

В целом наибольший объем ответов был получен относительно средств организации (29 индикаторов) и ценностей (22 индикаторов). Минимальное число ответов было получено относительно стратегий коррекции деятельности для выживания в период кризиса (1 индикатор). Цели организации, а также ожидания и прогнозы относительно выживания организации в период кризиса выявить не удалось.

На основе теоретического анализа могут быть реконструированы не все параметры организационной культуры научных организаций советского периода: 1) средства (высокий социально-экономический статус); 2) критерии оценки результатов деятельности (трудная применимость на практике, субъективность); 3) артефакты организационной культуры (свободный режим труда, недостаточность материального оснащения). 
Теоретический анализ литературы и анализ ответов участников фокус-групп позволяет говорить о том, что высокий социально-экономической статус научного работника советского периода не сохранился до настоящего времени, по-прежнему наблюдается затрудненность применения научных результатов в практике, недостаточность материального оснащения, достаточно свободный режим труда. Таким образом, в организационной культуре современной российской гуманитарной научной организации во многом сохраняются элементы, унаследованные ею от советской гуманитарной научной организации. Изменению подвергся дишь социально-экономический статус ученых.

\section{ЗАКАЮЧЕНИЕ}

Национальная культура оказывает влияние на организационную культуру и на научную культуру конкретной страны. Центральной составляющей культуры являются ценности. При осуществлении реформы организации важно проанализировать ее историю и организационную культуру и, отталкиваясь от нее, осуществлять модернизацию.

В связи с тем что наиболее значимыми ценностями Института психологии РАН как организации являются свобода и сохранение традиций, его реформирование не должно носить резкий и радикальный характер, а должно осуществляться постепенно. Важным является также сохранение свободы режима труда и научного поиска сотрудников. В связи с тем что материальная ориентированность никогда не была (и даже с наступлением нового социально-экономического строя так и не стала) организационной ценностью и стимулом для осуществления научных исследований, но лишь средством, привязывать финансирование Института психологии РАН к объему выпускаемой им научной продукции нецелесообразно. Хорошим стимулом для научных исследований должна стать их социальная востребованность.

Выдвинутое предположение о сходстве организационной культуры советской гуманитарной научной организации и современной в основном подтвердилось.

\section{СПИСОК АИТЕРАТУРЫ}

Аллахвердян, А. Г. (2014) Аинамика научных кадров в советской и российской науке: сравнительно-историческое исследование. М. : Когито-Центр. 263 с.

Белкин, П. Г., Емельянов, Е. Н., Иванов, М. А. (1987) Социальная психология научного коллектива. М. : Наука. 214 с.

Аежина, И. Г. (2006) Механизмы государственного финансирования науки в России. М. : ИЭПП. 130 c.

Аежина, И. Г. (2008) Государственное регулирование науки в России. М. : Магистр. 430 с. Аежина, И. Г., Грэхем, $\Lambda$. (2009) Наука в новой России: кризис, помощь, реформы. Ростов н/А. : Иза-во Южн. федер. ун-та. 240 с.

Иванова, Н. И. (2001) Формирование и эволюция национальных инновационных систем. М. : ИМЭМО РАН. 155 с.

Каган, М. С. (1997) Философская теория ценности. СПб. : Петрополис. 205 с.

Коннов, В. И. (2014) Социально-психологические основы национальной научно-исследовательской культуры // Психологический журнал. Т. 35. № 5. С. 19-27.

$\Lambda$ евченко, Е. В. (2006) Отображение психоанализа в отечественных учебниках // Meтодология и история психологии. Т. 1. Вып. 2. С. 128-137. 
Иипатов, С. А. (1997) Организационная культура: концептуальные модели и методы диагностики // Вестн. Моск. ун-та. Сер. 14. Психология. № 4. С. 55-65.

Аук, А. Н. (1982) Роль ученых-организаторов в развитии науки. Научно-аналитический обзор. М. : ИНИОН. 46 с.

Проблема эффективности труда ученого (1984). Реферат. сб. / отв. ред. А. А. Игнатьев. М. : ИНИОН. 272 с.

Семенов, Е. В. (2008) Человеческий капитал в российской науке // Информационное общество. Вып. 1-2. С. 106-123.

Тихомирова, О. Г. (2008) Организационная культура: формирование, развитие и оценка. СПб. : ИТМО. 154 с.

Ушаков, А. В., Валуева, Е. А. (2006) Параллельные открытия в отечественной и зарубежной психологии: пример интуиции и имплицитного научения // Образ российской психологии в регионах страны и в мире : мат. Междунар. форума и Школы молодых ученых ИП РАН, 24-28 сентября 2006 г. / отв. ред. А. А. Алексапольский, И. С. Кострикина, А. В. Юревич. М. : ИзА-во «Институт психологии РАН». 431 с. С. 32-44.

Чернышев, А. С., Сарычев, С. В., Елизаров, С. Г. (2015) К вопросу о перспективах отечественной психологии в решении задач российского общества // Психологический журнал. Т. 36. № 2. С. 113-119.

Шейн, Э. Х. (2002) Организационная культура и лидерство. СПб. : Питер. 336 с.

Юревич, А. В. (2008) Ценностные основания психологической науки // Ценностные основания психологической науки и психология ценностей / отв. ред. В.В.Знаков, Г. В. Залевский. М. : ИзА-во «Институт психологии РАН». 344 с. С. 21-40.

Юревич, А. В. (2015) Имеет ли наука национальные особенности? // Психологический журнал. Т. 36. № 1. С. 123-132.

Юревич, А. В., Цапенко, И. П. (2010) Наука в современном российском обществе. М. : ИзА-во «Институт психологии РАН». 335 с.

Balzer, H. D. (1989) Soviet science on the edge of reform. Boulder : Westview. 290 p.

Deal, T. E., Kennedy, A. A. (1982) Corporate cultures: The rites and rituals of corporate life. Reading : Addison-Wesley Publishing Company. 232 p.

Jaques, E. (1951) The changing culture of factory. L. : Tavistock Institute. $341 \mathrm{p}$.

Michon, C., Stern, P. (1985) La dynamisation sociale. P. : Ed. d'organisation. 115 p.

Mohan, M. L. (1993) Organizational communication and cultural vision. Albany : State University of New York Press. 202 p.

Ouchi, W. G. (1981) Theory Z : How American Business Can Meet the Japanese Challenge. Reading : Addison-Wesley Publishing Company. 192 p.

Peters, T. J., Waterman, R. H. (1982) In search of excellence : Lessons from America's BestRun Companies. N. Y. : Harper and Row. 360 p.

Whyte, W. H. (1956) The organization man. N. Y. : Doubleday. 471 p.

Аата поступления: 11.03.2016 г.

THE ORGANIZATIONAL CULTURE OF RUSSIAN RESEARCH INSTITUTIONS IN THE HUMANITIES (THE INSTITUTE OF PSYCHOLOGY, RUSSIAN ACADEMY

OF SCIENCES)

A. E. VOROBYOVA

(INSTITUTE OF PSYCHOLOGY, RUSSIAN ACADEMY OF SCIENCES)

The article investigates the organizational culture of research institutions as part of national research culture. It has acquired a special importance in the contemporary situation of organizational reforms of Russian science. 
We understand organizational culture as a value-related characteristic, which develops in accordance with the field the institution belongs to. The research values of a specific institution correlate both with the common values of global science and those of national culture. During the Soviet period, the most typical factors of scientific institutions and their work included the following: low usability of research outcomes, highly subjective research assessment, flexible working hours and low level of procurement. The current situation in Russian science is characterized by a different set of problems: low salaries and socioeconomic status, the aging of personnel, dual employment, etc.

The article presents the outcomes of a study conducted by the author in 2015 on four focus groups comprising 20 staffmembers of several laboratories of the Institute of Psychology, Russian Academy of Sciences. Our method was based on Edgar H. Schein holistic theory of organizational culture. In accordance with its principles, we have drafted a group interview model. Content analysis of the completed interviews allowed us to outline the value structure and the basic views of the institute's organizational culture as seen by its staff members. Researchers were found to give clear preference to the values of academic freedom and continuity of tradition and to the basic assumptions of freedom and school of research.

Thus we have found that the organizational culture of contemporary Russian research institution in the humanities largely preserves the features it has inherited from the Soviet times.

Keywords: Institute of Psychology, Russian Academy of Sciences; organizational culture; basic assumptions; research institutions in the humanities; research culture; research values

\section{REFERENCES}

Allaverdian, A. G. (2014) Dinamika nauchnykb kadrov $v$ sovetskoi $i$ rossiiskoi nauke: sravnitel' no-istoricheskoe issledovanie. Moscow, Kogito-Tsentr. 263 p. (In Russ.).

Belkin, P. G., Emel'ianov, E. N. and Ivanov, M. A. (1987) Sotsial'naia psibologiia nauchnogo kollektiva. Moscow, Nauka. 214 p. (In Russ.).

Dezhina, I. G. (2006) Mehanizmy gosudarstvennogo finansirovaniia nauki $v$ Rossii. Moscow, IEPP. 130 p. (In Russ.).

Dezhina, I. G. (2008) Gosudarstvennoe regulirovanie nauki v Rossii. Moscow, Magistr. 430 p. (In Russ.).

Dezhina, I. G. and Graham, L. (2009) Nauka v novoi Rossii: krizis, pomoshch, reformy. Rostov na Donu, Yuzhn. feder. un-t Publ. 240 p. (In Russ.).

Ivanova, N. I. (2001) Formirovanie i evoliutsia natsional' nykb innovatsionnykb sistem. Moscow, IMEMO RAN. 155 p. (In Russ.). Russ.).

Kagan, M. S. (1997) Filosofskaia teoria tsennosti. St. Petersburg, Petropolis. 205 p. (In

Konnov, V. I. (2014) Sotsial'no-psikhologicheskie osnovy natsional'noi nauchno-issledovatel'skoi kul'tury. Psibologicheskii zhurnal, vol. 35, no. 5, pp. 19-27. (In Russ.).

Levchenko, E. V. (2006) Otobrazhenie psikhoanaliza v otechestvennykh uchebnikakh. Metodologia $i$ istoriia psibologii, vol. 1, issue 2, pp. 128-137. (In Russ.).

Lipatov, S. A. (1997) Organizatsionnaia kul'tura: kontseptual'nye modeli i metody diagnostiki. Vestnik Moskovskogo universiteta, issue 14, Psikhologiia, no. 4, pp. 55-65. (In Russ.).

Luk, A. N. (1982) Rol' uchenykb-organizatorov v razvitii nauki. Nauchno-analiticheskii obzor. Moscow, INION. 46 p. (In Russ.).

Problema effektivnosti truda uchenogo (1984). Referat. sb., ed. A. A. Ignat'ev. Moscow, INION. 272 p. (In Russ.). 
Semenov, E. V. (2008) Chelovecheskii kapital v rossiiskoi nauke. Informatsionnoe obshchestvo, issue 1-2, pp. 106-123. (In Russ.).

Tikhomirova, O. G. (2008) Organizatsionnaia kul'tura: formirovanie, razvitie i otsenka. St. Petersburg, ITMO. 154 p. (In Russ.).

Ushakov, D. V. and Valueva, E. A. (2006) Parallel'nye otkrytia v otechestvennoi i zarubezhnoi psikhologii: primer intuitsii i implitsitnogo naucheniia. In: Obraz rossiiskoj psibologii $v$ regionakh strany i v mire: mat. Mezhdunar. Foruma i Shkoly molodykb uchenykb IP RAN, 24-28 sentiabria 2006 g., ed. A. A. Aleksapol'skii, I. S. Kostrikina and A. V. Yurevich. Moscow, Institut psihologii RAN Publ. 431 p. Pp. 32-44. (In Russ.).

Chernyshev, A. S., Sarychev, S. V. and Elizarov, S. G. (2015) K voprosu o perspektivakh otechestvennoi psikhologii v reshenii zadach rossiiskogo obshchestva. Psibologicheskii zhurnal, vol. 36, no. 2, pp. 113-119. (In Russ.). Russ.).

Schein, E. H. (2002) Organizatsionnaia kul' tura i liderstvo. St. Petersburg, Piter. 336 p. (In

Yurevich, A. V. (2008) Tsennostnye osnovaniia psikhologicheskoi nauki. In: Tsennostnye osnovaniia psikbologicheskoi nauki i psikbologiia tsennostei, ed. V. V. Znakov and G. V. Zalevskii. Moscow, Institut psikhologii RAN Publ. 344 p. Pp. 21-40. (In Russ.).

Yurevich, A. V. (2015) Imeet li nauka natsional'nye osobennosti? Psibologicheskii zhurnal, vol. 36, no. 1, pp. 123-132. (In Russ.).

Yurevich, A. V. and Tsapenko, I. P. (2010) Nauka v sovremennom rossiiskom obshchestve. Moscow, Institut psikhologii RAN Publ. 335 p. (In Russ.).

Balzer, H. D. (1989) Soviet science on the edge of reform. Boulder, Westview. 290 p.

Deal, T. E. and Kennedy, A. A. (1982) Corporate cultures: The rites and rituals of corporate life. Reading : Addison-Wesley Publishing Company. 232 p.

Jaques, E. (1951) The changing culture of factory. London, Tavistock Institute. 341 p.

Michon, C. and Stern, P. (1985) La dynamisation sociale. Paris, Ed. d'organisation. 115 p.

Mohan, M. L. (1993) Organizational communication and cultural vision. Albany, State University of New York Press. 202 p.

Ouchi, W. G. (1981) Theory Z: How American Business Can Meet the Japanese Challenge. Reading : Addison-Wesley Publishing Company. 192 p.

Peters, T. J. and Waterman, R. H. (1982) In search of excellence : Lessons from America's Best-Run Companies. N. Y.: Harper and Row. 360 p.

Whyte, W. H. (1956) The organization man. New York, Doubleday. 471 p.

Submission date: 11.03.2016.

Воробьева Анастасия Евгеньевна - кандидат психологических наук, старший научный сотрудник лаборатории социальной и экономической психологии Института психологии Российской академии наук. Адрес: 129366, Россия, г. Москва, ул. Ярославская, А. 13, корп. 1. Тел.: +7 (495) 682-01-40. Эл. адpec: aeVorobieva@yandex.ru

Vorobyova Anastasia Evgenyevna, PhD, Senior Research Fellow, Laboratory of Social and Economic Psychology, Institute of Psychology, Russian Academy of Sciences. Postal address: Bldg. 1, 13 Yaroslavskaya St., 129366 Moscow, Russian Federation. Tel.: +7 (495) 682-01-40. E-mail:aeVorobieva@yandex.ru 